\title{
Astronomy in Serbia and Serbia in the International Astronomical Union
}

\section{Bojan Arbutina and Olga Atanacković}

\author{
Department of Astronomy, Faculty of Mathematics, University of Belgrade, Studentski trg 16, \\ 11000 Belgrade, Serbia \\ email: arbo@math.rs, olga@math.rs
}

\begin{abstract}
We briefly discuss the history of membership and the current position of Serbia inside the International Astronomical Union. We give an overview of astronomy education, research and public outreach in Serbia. Some statistics are presented concerning the number and gender of BSc, MSc and PhD students that graduated/obtained their degree in astronomy/astrophysics from the Department of Astronomy, Faculty of Mathematics, University of Belgrade. Due attention is paid to the most important scientific/educational institutions in Serbia in which the majority of astronomers are employed as well as various research topics investigated.
\end{abstract}

Keywords. History and philosophy of astronomy, sociology of astronomy, astronomy in Serbia

\section{Primary school education}

In the primary schools in Serbia astronomy topics are taught as part of the curricula of the course of Geography (V grade). Apart from the obligatory programme, additional astronomical topics are taught as part of the activity of astronomy clubs organized by the enthusiastic teachers of physics, mathematics or geography in some primary schools (Atanacković 2017, 2018).

\section{Secondary school education}

From 1969 to 1994 Astronomy has been a separate and compulsory fourth grade one hour per week course. In 1990 astronomy topics became incorporated in the final IV grade Physics courses. Since then, numerous attempts have been made to reintroduce astronomy as a separate (either compulsory or elective) subject, but still without success. New standards for teaching of Physics are introduced in the framework of the reform of the secondary schools education, but, unfortunately, in these reformed standards astronomy is still regarded as a part of Physics.

At regular annual meetings of physics teachers organized by the Serbian Physical Society, irregularly there is one lecture on the topics related to astronomy (Ilić 2014; Arbutina 2018). Since May 2014 the students of the Department of Astronomy of the Faculty of Mathematics, University in Belgrade have organized four Schools of Astronomy for young people (age 15 to 25), mainly for secondary school students. Two-hour lectures have been given twice a week.

The Petnica Science Centre (PSC) is the biggest and the oldest centre for extracurricular (informal) education in the south-east of Europe (http://www.psc.ac.rs). The two cycles of seminars in astronomy organized by the PSC are described in more detail in Atanacković (2009). Apart from attending lectures, participants are also engaged in individual small research projects, the best of which are published in the Petničke sveske (Petnica Notebooks). The Petnica Summer Institute (PSI) - an annual international 


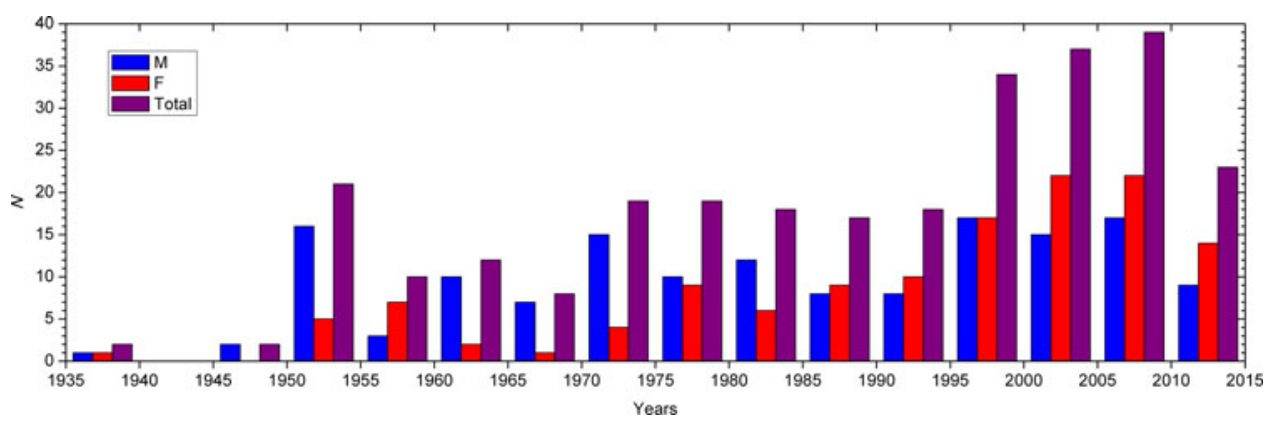

Figure 1. Number of male, female students and the total number of students that graduated from the Department of Astronomy, Faculty of Mathematics, University of Belgrade in 5-year periods from 1935 to 2015.

summer school for undergraduate and early graduate students - has been organized since 2013 by a group of senior associates of the Department of Astronomy at PSC. It has participants and lecturers from all over the world and covers topics in theoretical (astro)physics that change in a four year cycle (cosmology, high energy physics, astrophysics and astroparticle physics and general relativity).

Back in 2002 late Prof. Jelena Milogradov-Turin initiated the participation of Serbia in the international astronomy olympiads (Milogradov-Turin 2003). Serbian teams have participated at two olympiads: since 2002 at International Astronomy Olympiad (IAO), founded in Russia in 1996, and since 2009 at International Olympiad of Astronomy and Astrophysics (IOAA), founded on the initiative of Thailand, Indonesia, Iran, China and Poland in 2007. Since 2013 Serbia also participated in the Saint-Petersburg Astronomical Olympiad. Serbia was nominated and accepted to host the 15 th IOAA in 2021 (Vidojević et al. 2018).

\section{University education in astronomy}

Astronomy courses are taught at five state universities in Serbia: University of Belgrade, University of Novi Sad, University of Niš, University of Kragujevac and University of Priština in Kosovska Mitrovica. Astronomy/astrophysics undergraduate programmes exist at the University of Belgrade and recently (2002-2018) at the University of Novi Sad (Atanacković 2013, 2017, 2018). The University of Belgrade is the only university with a separate department of astronomy (at the Faculty of Mathematics) and the one that is producing the majority of students with BSc, MSc or PhD degree in astronomy/astrophysics. So far 297 students have graduated from the Department of Astronomy, Faculty of Mathematics, University of Belgrade (since 1936) (see "BAZA" at http://alas.math.rs/ astrobaza/, Atanacković et al. 2009), 36 students received the Master degree (model 4+1, since 2007), 69 students received the MSc degree (1968-2010), and 56 students the $\mathrm{PhD}$ degree (since 1958).

In Figs. 1-4 we give some statistics of BSc and PhDs. As of October 2017, there are 156 male $(52.5 \%)$ and 141 female $(47.5 \%)$ BSc students. Concerning PhDs, there are 40 males $(71.4 \%)$ and 16 females $(28.6 \%)$. We have shown cumulative numbers for both, BSc and $\mathrm{PhDs}$, and in the latter case we also fitted the data with a simple population-growth model

$$
\frac{d N}{d t}=\alpha N+\beta
$$

where the increase of the $\mathrm{PhD}$ population is proportional to the number of individuals at a given time ( $\mathrm{PhDs}$ produce more $\mathrm{PhDs}$ ) plus some constant term (even if there are 


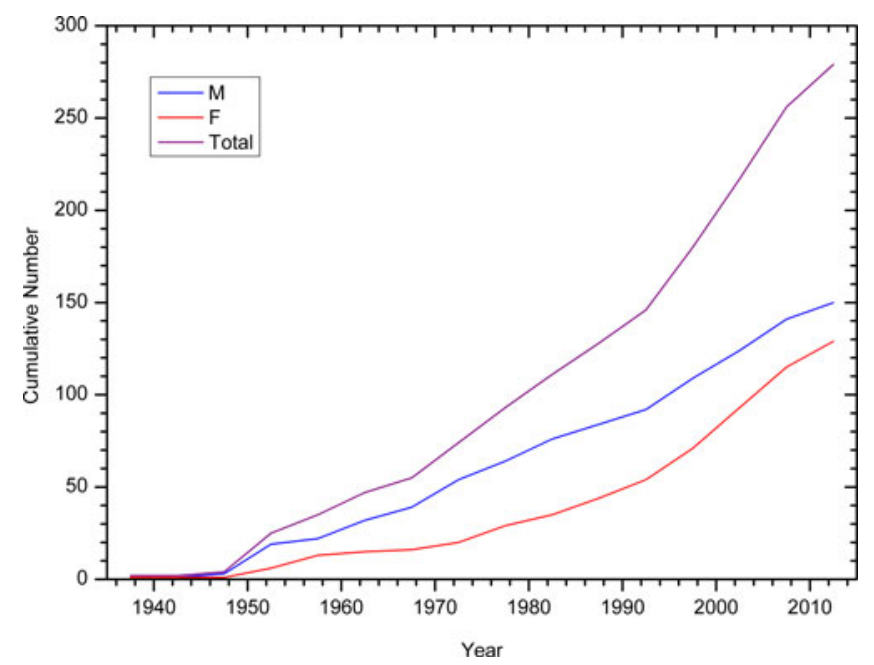

Figure 2. Cumulative numbers of graduated students according to gender, and the total number.

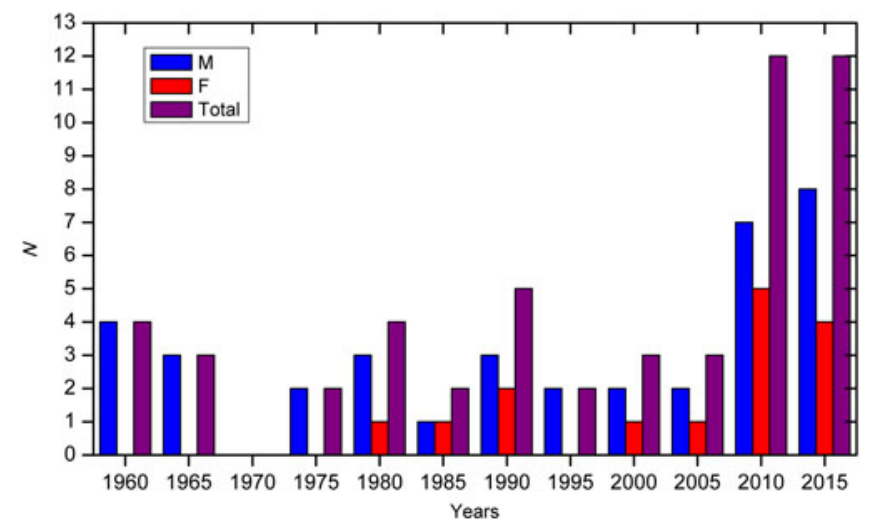

Figure 3. The same as in Fig. 1, only for students that obtained PhD degree.

no PhDs, they are, let us assume constantly, produced by e.g. advisors from abroad). This gives rise to an exponential growth at a later moment. The parameters of the fit are $\beta=0.05$ i.e. 5 PhDs in 100 years, while the e-folding time is $1 / \alpha=35$ years, which, if this trend continues, allows us to estimate the number of PhDs by 2040 to be 100. Many of our former students work and study at universities and institutes worldwide. To account for all of them in a similar statistical analysis to this one, would require more thorough research that we leave for some time in the future.

Since 2011 the University of Belgrade has participated in a 2-year European Erasmus Mundus Joint Master programme in astronomy and astrophysics, AstroMundus, together with four more universities: Innsbruck (coordinator), Rome 2, Padova and Göttingen (see http://www.astromundus.eu). The University of Belgrade (Faculty of Mathematics) offers the 3rd and the 4th semester of the Master programme. From school year 2011/2012 there were six classes of students. Several dozen students in total were enrolled at Belgrade University from all over the world (Bangladesh, Chile, China, Croatia, Columbia, Finland, Georgia, India, Italy, Ireland, Macedonia, Mexico, Pakistan, Peru, Slovenia, Spain, Turkey, UK, USA, Venezuela, etc). 


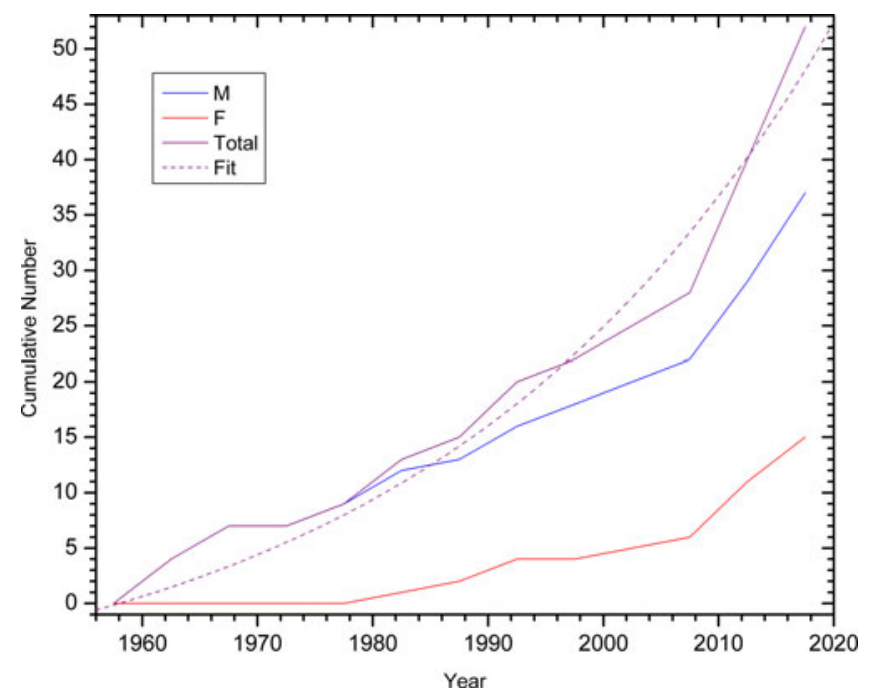

Figure 4. The same as in Fig. 2, only for students that obtained PhD degree plus a model fit to the total number.

\section{Professional institutions and organizations}

Professional astronomers in Serbia find employment primarily in two institutions: Astronomical Observatory of Belgrade (http://www.aob.rs/), founded in 1887, and Department of Astronomy, Faculty of Mathematics, University of Belgrade (http://astro.math.rs/). As of January 2018, according to the institutions' websites, there are 42 research staff members at the Astronomical Observatory and 19 teaching and research staff members at the Department of Astronomy. Several astronomers/astrophysicists also work at the University of Novi Sad, University of Kragujevac and State University of Novi Pazar, and a number of those who have either graduated or obtained a PhD in astronomy from the University of Belgrade work at the Mathematical Institute of Serbian Academy of Sciences and Arts, Institute of Physics in Zemun, Vinča Institute for Nuclear Sciences, etc.

As a result of light pollution, the Astronomical Observatory of Belgrade is no longer suitable for professional astronomical observations and its 65-cm Large Refractor is rarely used. The Astronomical Station Vidojevica is a new observation site established by the Astronomical Observatory of Belgrade, located on Mt Vidojevica near Prokuplje, at an altitude of $1150 \mathrm{~m}$ (see Bogosavljević 2013). It has a 60-cm telescope and a new 1.4-m telescope "Milanković", which is mounted temporarily in a roll-off roof pavilion in May/June 2016, while its permanent dome is being constructed on the site.

Since 1947 Astronomical Observatory has been publishing the Publications of the Astronomical Observatory of Belgrade, which include mainly conference proceedings and monographs, and since 1998, together with the Faculty of Mathematics, it has published a biannual scientific journal Serbian Astronomical Journal (http://saj.math.rs, previously Bulletin Astronomique de Belgrade (1992-1997) and Bulletin de l'Observatoire Astronomique de Belgrade (1936-1991)) that is currently included in the Clarivate Analytics' Web of Science and Journal Citation Report (Arbutina 2013; Knežević et al. 2017; JCR 2018).

Serbian astronomers are gathered in a professional organization under the name of the "Society of Astronomers of Serbia" (SAS), founded in 1981. The seat of the SAS is in Belgrade. Before its foundation, astronomers of Serbia were organized within the Society of Mathematicians and Physicists of Serbia (since its foundation in 1948) and by this 
Society within the Union of Societies of Mathematicians and Physicists of Yugoslavia (since its foundation in 1949). Both organizations incorporated astronomers officially in its title, in 1962 and 1966, respectively. Today, the Society has about 90 members, both professionals and distinguished amateur astronomers.

The SAS is the adhering organization representing Serbia in the International Astronomical Union (IAU). As of November 2017 the president of SAS is Dr Nemanja Martinović, while the president of the National Committee for Astronomy (NCA) is Dr Bojan Arbutina.

\section{Public outreach}

Public outreach in Serbia is realized mainly through the activities of 23 amateur astronomical societies (see Table 1 in Atanacković 2017), although professional astronomers from both universities and institutes are also quite active in promotion and popularization of astronomy. The society with the longest tradition is AS "Rudjer Bošković" (Belgrade), which celebrated 80 years of the Society, 60 years of the Public Observatory and 45 years of the Planetarium in 2014 (Aleksić \& Stanić 2017). In the same year the AS "ADNOS" (Novi Sad) celebrated 40 years since its foundation. Most of the societies and institutions participate in events like Night of Museums, Book Fair, Festival of Science, Night of Researchers, etc. The SAS and the Astronomical Society "Rudjer Bošković" were particularly active in using a mobile planetarium as a tool for astronomy communication. The National Outreach Coordinator for the IAU Office for Astronomy Outreach is Dr Tijana Prodanović.

Concerning the publishing activity, unfortunately, many popular magazines in Serbia have ceased to exist. Astronomy has been to some extent popularized by a quarterly magazine Mladi fizičar (Young Physicist). AS "Rudjer Bošković" publishes Publications of the Astronomical Society "Rudjer Bošković", which is more professionally oriented. It has also recently restarted the publication of a popular astronomical magazine Vasiona founded in 1952 (Dimitrijević 2018). The Astronomical Magazine - AM (http://www. astronomija.org.rs/) is the largest astronomical web-site in the country.

\section{Serbia in the IAU}

Although, as a member of the Allied Powers and a WWI winner, Serbia was one of the founding members of the International Research Council (Trimble 1997) in the context of which the IAU was established in 1919 (Blaauw 1994), Serbia, within the Kingdom of Yugoslavia, joined the IAU only in 1935. The formal representative from Yugoslavia at the V General Assembly in Paris, July 9-17, 1935, was Prof. Vojislav Mišković (from 1933 in Commission 20 Minor Planets, Mišković 1933), a member of the Serbian Royal Academy and the Director of the Astronomical Observatory of Belgrade (Mišković 1935; Stratton 1936). In 1938 Yugoslavia had six members in the IAU and the NCA president was Prof. Milutin Milanković (Oort 1939). After the WWII, in 1948, only two members were listed: V. Mišković and M. Milanković (Oort 1950), while in 1991 there were 39 Yugoslav members in total (Bergeron 1992). Following the breakup and war in the former Yugoslavia, Serbia and Montenegro, joined together in the so-called Federal Republic of Yugoslavia, were excluded from the IAU, to be admitted again in 2003. Serbia succeeded the membership after the breakup with Montenegro in 2006.

As of January 2018, there are 50 individual IAU members registered in the database with Serbia as the National Member country. Ten potential new members (one individual and nine junior) have been nominated by Serbia's NCA for the XXXth IAU General Assembly. 


\section{References}

Aleksić, J., \& Stanić, N. 2017, Publ. Astron. Obs. Belgrade, 96, 469

Arbutina, B. 2013, Serb. Astron. J., 186, 77

Arbutina, B. 2018, Zbornik radova sa XXXVI Republickog seminara o nastavi fizike, Nastava fizike, 6, 47

Atanacković, O. 2009, Publ. Astron. Obs. Belgrade, 86, 231

Atanacković, O., Vitas, N., \& Arbutina, B. 2009, Publ. Astron. Obs. Belgrade, 86, 369

Atanacković, O. 2013, Publ. Astron. Obs. Belgrade, 92, 107

Atanacković, O. 2017, Publ. Astron. Obs. Belgrade, 96, 397

Atanacković, O. 2018, Publ. Astron. Obs. Belgrade, 98, 91

Blaauw, A. 1994, History of the IAU (Dordrecht: Kluwer)

Bergeron, J. (ed.) 1992, Transactions of the IAU B, XXI, M2

Bogosavljević, M. 2013, Publ. Astron. Obs. Belgrade, 92, 31

Dimitrijević, M. S. 2018, Vasiona, LX(1-2), 1

Ilić, D. 2014, Zbornik predavanja sa XXXII Republickog seminara o nastavi fizike, 27

JCR 2018, 2017 Journal Citation Reports (Philadelphia: Clarivate Analytics)

Knežević, Z., Urošević, D., \& Arbutina, B. 2017, Publ. Astron. Obs. Belgrade, 96, 523

Milogradov-Turin, J. 2003, Vasiona, LI(3), 57

Mišković, V. (ed.) 1933, Godišnjak našeg neba za god. 1934, V, 153

Mišković, V. (ed.) 1935, Godišnjak našeg neba za god. 1936, VII, 244

Oort, J. H. (ed.) 1939, Transactions of the IAU B, VI, 502

Oort, J. H. (ed.) 1950, Transactions of the IAU B, VII, 528

Stratton, F. J. M. (ed.) 1936, Transactions of the IAU B, V, 414

Trimble, V. 1997, Beam Line, 27(4), 43

Vidojević, S., Ninković, S., Simonović, B., \& Bešlić, I. 2018, Publ. Astron. Obs. Belgrade, 98, 217 